\title{
Retrospective analysis of LNM risk factors and the effect of chemotherapy in early colorectal cancer: A Chinese multicenter study
}

Chunyan Zeng ${ }^{1 \dagger}$, Dandan Xiong ${ }^{1 \dagger}$, Fei Cheng ${ }^{1,2+}$, Qingtian Luo ${ }^{3}$, Qiang Wang ${ }^{4}$, Jun Huang ${ }^{5}$, Guilian Lan ${ }^{1}$, Huan Zhong ${ }^{6}$ and Youxiang Chen $^{1 *}$ (D)

\begin{abstract}
Background: Estimating the risk of lymph node metastasis (LNM) is crucial for determining subsequent treatments following curative resection of early colorectal cancer (ECC). This multicenter study analyzed the risk factors of LNM and the effectiveness of postoperative chemotherapy in patients with ECC.

Methods: We retrospectively analyzed the data of 473 patients with ECC who underwent general surgery in five hospitals between January 2007 and October 2018. The correlations between LNM and sex, age, tumor size, tumor location, endoscopic morphology, pathology, depth of invasion and tumor budding (TB) were directly estimated based on postoperative pathological analysis. We also observed the overall survival (OS) and recurrence in ECC patients with and without LNM after matching according to baseline measures.

Results: In total, 473 ECC patients were observed, 288 patients were enrolled, and 17 patients had LNM (5.90\%). The univariate analysis revealed that tumor size, pathology, and lymphovascular invasion were associated with LNM in ECC ( $P=0.026,0.000$, and 0.000 , respectively), and the multivariate logistic regression confirmed that tumor size, pathology, and lymphovascular invasion were risk factors for $\operatorname{LNM}(P=0.021,0.023$, and 0.001 , respectively). There were no significant differences in OS and recurrence between the ECC patients with and without LNM after matching based on baseline measures $(P=0.158$ and 0.346 , respectively), and no significant difference was observed between chemotherapy and no chemotherapy in ECC patients without LNM after surgery $(P=0.729$ and 0.052).

Conclusion: Tumor size, pathology, and lymphovascular invasion are risk factors for predicting LNM in ECC patients. Adjuvant chemotherapy could improve OS and recurrence in patients with LNM but not always in ECC patients without LNM.
\end{abstract}

Keywords: Early colorectal cancer, Chemotherapy, Lymph node metastasis, Risk factors, Overall survival, Recurrence

\footnotetext{
* Correspondence: chenyx102@126.com

${ }^{\dagger}$ Chunyan Zeng, Dandan Xiong and Fei Cheng contributed equally to this work.

'Department of Gastroenterology, the First Affiliated Hospital of Nanchang University, 17 Yongwaizheng Street, Nanchang 330006, Jiangxi, China Full list of author information is available at the end of the article
}

C C The Author(s). 2020 Open Access This article is licensed under a Creative Commons Attribution 4.0 International License, which permits use, sharing, adaptation, distribution and reproduction in any medium or format, as long as you give appropriate credit to the original author(s) and the source, provide a link to the Creative Commons licence, and indicate if changes were made. The images or other third party material in this article are included in the article's Creative Commons licence, unless indicated otherwise in a credit line to the material. If material is not included in the article's Creative Commons licence and your intended use is not permitted by statutory regulation or exceeds the permitted use, you will need to obtain permission directly from the copyright holder. To view a copy of this licence, visit http://creativecommons.org/licenses/by/4.0/. The Creative Commons Public Domain Dedication waiver (http://creativecommons.org/publicdomain/zero/1.0/) applies to the data made available in this article, unless otherwise stated in a credit line to the data. 


\section{Background}

Recently, as a result of the advocacy for endoscopic screening projects, the number of documented cases of early colorectal cancer (ECC) has increased [1]. ECC is defined as cancer located in the mucosa or submucosa with or without lymph node involvement (T1 TNM stage). Endoscopic treatment is absolutely the best choice of treatment for intramucosal ECC patients with no lymph node metastasis (LNM) and vascular invasion [2-4]. However, it has been reported that the LNM rate is as high as $7-15 \%$ in $\mathrm{T} 1$ colorectal cancer [5-8].

Therefore, endoscopic treatment can accomplish local primary tumor resection but not lymphadenectomy, and using this procedure for the radical excision of ECC with LNM undoubtedly must increase the postoperative recurrence rate and unfavorable prognosis. Moreover, preoperatively determining whether ECC is associated with lymph node metastasis is critical for selecting a surgical approach and the extent of resection. Although previous studies have reported that poor differentiation, the submucosal invasion depth, lymphovascular invasion, and tumor budding (TB) are risk factors for LNM, sufficient evidence suggesting that a particular risk factor affects long-term prognosis and the efficiency of postoperative chemotherapy is lacking. Thus, more evidence derived from long-term surveillance is needed. Furthermore, there is no consensus regarding the survival benefit of postoperative chemotherapy in early colon cancer [9].

In this study, our aim is to further analyze the risk factors in ECC patients with LNM in relation to various clinicopathologic characteristics. Moreover, we evaluate the effect of adjuvant chemotherapy following curative surgery.

\section{Methods}

\section{Patient selection and data collection}

The demographic and clinical data of 473 individuals who underwent endoscopic treatment and general surgery in our hospital and four other affiliated hospitals were retrospectively collected between January 2007 and August 2018. The inclusion criteria were as follows: all cases diagnosed with ECC by a postoperative pathological analysis. The exclusion criteria were as follows: recurrence after surgical resection, advanced colorectal cancer, presence of other primary malignant tumors, patients undergoing perioperative radiotherapy and preoperative chemotherapy, endoscopic resection of ECC and patients with familial adenomatous polyposis. Finally, all patients (288 patients after surgery) in the Jiangxi Province region were followed until November 30th, 2018 (Fig. 1). Moreover, the following data associated with chemotherapy were recorded: regimens, drugs, and times of treatment. The indications for chemotherapy were the presence of LNM or risk factors for LNM in ECC patients, such as poorly differentiated carcinomas, submucosal invasion, lymphovascular invasion, or TB. We established a collaborative study group involving five hospitals in two cities of Jiangxi Province, China. The study group confirmed that the design and data collection of this retrospective research were performed in accordance with the relevant guidelines and regulations. The clinical data was acquired with the approval and permission of the Institutional Review Board of the First Affiliated Hospital of Nanchang University.

\section{Clinicopathological parameters}

The following demographic and clinicopathological data were recorded: sex, age, tumor size (in maximum diameter), tumor location, endoscopic morphological type, depth of invasion, pathology, lymphovascular invasion, TB and LNM. The tumor differentiation data are based on the 2010 WHO colorectal cancer pathology grading standard as follows: colorectal cancer is divided into highly differentiated, moderately differentiated, poorly differentiated, and undifferentiated carcinoma. According to the morphology of the tumor under endoscopy, ECC is divided into the uplift type (Ip, Isp, and Is), the flat type (IIa, IIb, IIa + dep, nongranular type LST, and granular LST), and the concave type (IIc, IIc + IIa, and Is+IIc).

\section{Statistical analysis}

IBM SPSS statistics (version 20.0) was applied for the statistical analysis. A chi-squared test or t-test was used to analyze the relationship between the clinicopathological data and LNM in ECC. A logistic regression was used for the multivariate analysis of the factors identified as significant in the univariate analysis. A log-rank test was used in the tumor recurrence and overall survival analysis. $P<$ 0.05 was considered indicative of statistical significance.

\section{Results}

\section{Clinicopathological parameters (Table 1)}

Two hundred and eighty-eight patients who underwent surgery with or without lymph node dissection were enrolled (male:female $=162: 126$ ). The age of the patients ranged from 27 to 82 years. The cancer was located in the rectum in 186 patients, sigmoid colon in 68 patients, ascending colon in 16 patients, descending colon in 10 cases, and transverse colon in 4 cases. Based on the endoscopic morphological classification, there were 248 cases of type I (including the uplift type, Ip, Isp, and Is), 7 cases of type II (including the flat type, IIa, IIb, IIa + dep, nongranular type LST, and granular LST), and 25 cases of type III (including the concave type, IIc, IIc + IIa, and Is+IIc). The diameter of the mass ranged from 7 to $120 \mathrm{~mm}$ $(30.0 \pm 15.6 \mathrm{~mm})$. Regarding the pathological grading, 78 cases were highly differentiated, 202 cases were moderately differentiated, and 8 cases were poorly 


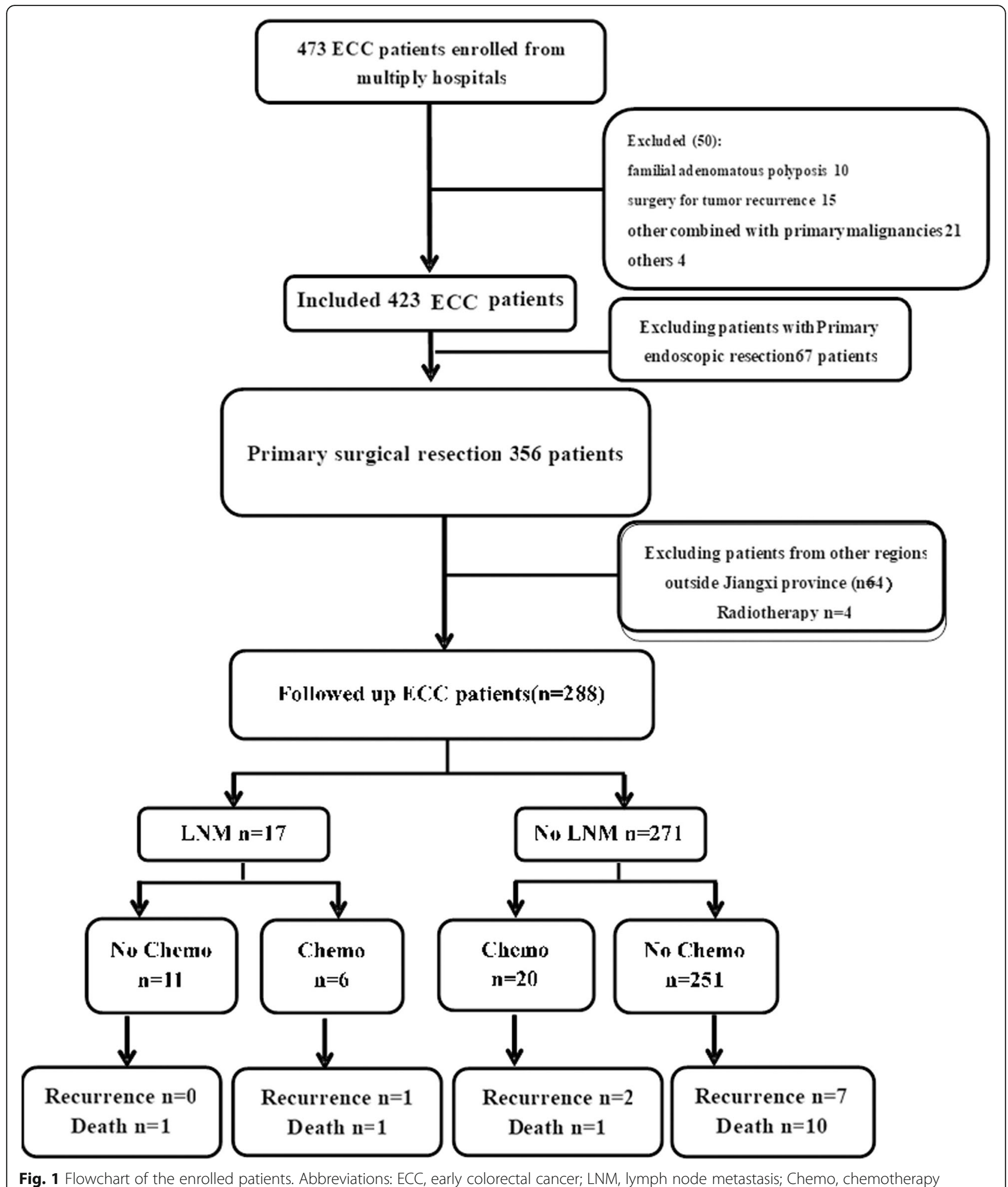

differentiated. As for the depth of invasion, 76 cases infiltrated the mucosal layer, while 212 cases infiltrated the submucosal layer. In total, 6 patients had lymphovascular invasion, and 3 cases had TB.
Univariate analysis of the factors associated with LNM in ECC

LNM was more prevalent among the patients with a larger tumor size $(P=0.026<0.05)$. Furthermore, the rate 
Table 1 Univariate analysis of risk factors and occurrence of lymph node metastasis

\begin{tabular}{|c|c|c|c|c|}
\hline Factors & $\mathrm{N}$ & $\operatorname{LNM}(-), \mathrm{n}(\%)$ & $\operatorname{LNM}(+), \mathrm{n}(\%)$ & $P$-value \\
\hline $\mathbf{N}$ & 288 & 271 & 17 & \\
\hline Gender & & & & 0.431 \\
\hline Male & 162 & $154(53.47)$ & $8(47.06)$ & \\
\hline Female & 126 & $117(46.53)$ & $9(52.94)$ & \\
\hline Age, $X \pm S D$ (years old) & $59.5+11.6$ & $59.7+11.7$ & $56.8+11.2$ & 0.316 \\
\hline Smoking & & & & 0.084 \\
\hline Positive & 68 & $67(23.26)$ & $1(5.88)$ & \\
\hline Negative & 220 & $204(76.74)$ & $16(94.12)$ & \\
\hline Alcohol & & & & 0.520 \\
\hline Positive & 43 & $41(15.13)$ & $2(11.76)$ & \\
\hline Negative & 245 & $230(84.87)$ & $15(88.24)$ & \\
\hline Family history & & & & 0.557 \\
\hline Positive & 10 & $10(3.69)$ & $(0.00)$ & \\
\hline Negative & 278 & $261(96.31)$ & $17(100.00)$ & \\
\hline Tumor size, $X \pm S D(\mathrm{~mm})$ & $30.0 \pm 15.6$ & $29.2 \pm 15.4$ & $38.3 \pm 17.3$ & $0.026^{*}$ \\
\hline Tumor location & & & & 0.115 \\
\hline Rectum & 186 & $171(63.10)$ & $15(88.24)$ & \\
\hline Sigmoid colon & 68 & $68(25.09)$ & 0 & \\
\hline Ascending colon & 19 & $17(6.27)$ & $2(11.76)$ & \\
\hline Descending colon & 10 & $10(3.69)$ & 0 & \\
\hline Transverse colon & 5 & $5(1.85)$ & 0 & \\
\hline Endoscopic morphology & & & & 0.703 \\
\hline I (the uplift type) & 248 & $232(85.61)$ & $16(94.12)$ & \\
\hline II (the flat type) & 7 & $7(2.58)$ & $0(0.00)$ & \\
\hline III (the concave type) & 25 & $24(8.86)$ & $1(5.88)$ & \\
\hline Uncertain & 8 & $8(2.95)$ & $0(0.00)$ & \\
\hline Pathology & & & & $<0.001^{* *}$ \\
\hline Highly differentiated & 78 & $78(28.78)$ & $0(0.00)$ & \\
\hline Moderately differentiated & 202 & $189(69.74)$ & $13(76.47)$ & \\
\hline Poorly differentiated & 8 & $4(1.48)$ & $4(23.53)$ & \\
\hline Depth of invasion & & & & 0.255 \\
\hline Mucosal layer & 76 & $74(27.31)$ & $2(11.76)$ & \\
\hline Submucosal layer & 212 & $197(72.69)$ & $15(88.24)$ & \\
\hline Lympho-vascular invasion & & & & $<0.001^{* *}$ \\
\hline Positive & 6 & $2(0.74)$ & $4(23.53)$ & \\
\hline Negative & 282 & $269(99.26)$ & $13(76.47)$ & \\
\hline Tumor budding & & & & 0.833 \\
\hline Positive & 3 & $3(1.11)$ & $0(0.00)$ & \\
\hline Negative & 285 & $268(98.89)$ & $17(100.00)$ & \\
\hline
\end{tabular}

Note: ${ }^{*} P<0.05,{ }^{*} P<0.01$. LNM(-):No lymph node metastasis, LNM(+):Lymph node metastasis

of LNM in the uplift type was higher than that in the other endoscopic types in all patients. In the LNM group, there were 4 cases with the poorly differentiated type $(23.53 \%$ vs. $1.48 \%$, LNM vs. no-LNM group), and the other cases presented with a moderately differentiated type $(76.47 \%$ vs. $69.74 \%$, LNM vs. no-LNM group) $(P<0.01)$. Regarding the depth of invasion, there were no significant differences $(P>0.05)$ between the LNM 
Table 2 Multivariate logistic regression analysis of ECC lymph node metastasis

\begin{tabular}{llll}
\hline Factors & OR & $\boldsymbol{P}$-value & $\mathbf{9 5 \%} \mathrm{Cl}$ \\
\hline Tumor size & 1.036 & $\mathbf{0 . 0 2 1} *$ & $1.005-1.068$ \\
Pathology differentiation & 8.877 & $\mathbf{0 . 0 2 3} *$ & $1.357-58.050$ \\
Lympho-vascular invasion & 0.039 & $\mathbf{0 . 0 0 1} *$ & $0.005-0.285$ \\
\hline
\end{tabular}

Note: ${ }^{*} P<0.05$

and no-LNM groups (88.24\% vs. 72.69\%). Furthermore, the rate of lymphovascular invasion in the cases with LNM was higher than that in those without LNM (23.53\% vs. $0.74 \%, P<0.001)$. The details of the comparisons and $P$-values are shown in Table 1.

The univariate analysis of the clinicopathological factors assessed in the patients with and without LNM revealed a significant relationship between LNM and the tumor size $(\mathrm{t}=-2.234, P=0.026<0.05)$, pathology differentiation, and lymphovascular invasion $\left(X^{2}=23.593\right.$, 40.734, both $P<0.001)$. The LNM rates were higher in the patients with poorly differentiated carcinomas, tumors with a large diameter, and lymphovascular invasion. However, sex, age, tumor location, endoscopic morphology, depth of invasion and TB were not statistically significantly associated with $\operatorname{LNM}(P=0.431,0.316$, $0.115,0.703,0.255$ and 0.833 , respectively; Table 1 ).

\section{Multivariate logistic regression analysis of the factors} associated with LNM in ECC

A multivariate logistic regression analysis was used for the multivariate analysis of the following factors identified as significant in the univariate analysis: tumor size, pathology differentiation and lymphovascular invasion. The analysis showed that tumor size, pathology differentiation and lymphovascular invasion were risk factors for LNM in ECC $(\mathrm{OR}=1.036$ and $P=0.021$; $\mathrm{OR}=8.877$ and $P=0.023 ; \mathrm{OR}=0.039$ and $P=0.001$; Table 2).

\section{Kaplan-Meier estimates of overall survival and recurrence rates associated with chemotherapy in the no-LNM ECC patients}

The overall survival and recurrence rate in the no-LNM ECC patients was determined by a Kaplan-Meier analysis on prognostic differences between the chemotherapy (20 cases included) and no-chemotherapy (251 cases included) groups. The 11-year overall survival rates and recurrence rates were $95.94 \%(260 / 271)$ and 3.32\% (9/271), respectively, in all 271 followed-up no-LNM ECC patients after surgery. Furthermore, 20 patients received chemotherapy after resection of the tumor, and 2 of these patients had recurrence, including 1 death. The main chemotherapy regimens included CapeOX (L-OHP + Cap) and FLOX (L$\mathrm{OHP}+\mathrm{CF}+5-\mathrm{FU})$, and the periods of treatment ranged from 4 to 12 weeks. In this study, the patients treated with chemotherapy after surgery did not exhibit differences in the overall survival rates $(95.0 \%$ vs. $96.02 \%, P=0.729>$ 0.05). Among the ECC patients without LNM, there were no significant differences between the chemotherapy and nonchemotherapy groups in overall survival and recurrence rates (Fig. 2).

Kaplan-Meier estimates of overall survival and recurrence rates in LNM and no-LNM ECC patients matches according to baseline measures

Seventeen ECC patients with LNM were matched with no-LNM patients. The baseline measure is shown in Table 3. However, more patients with LNM received

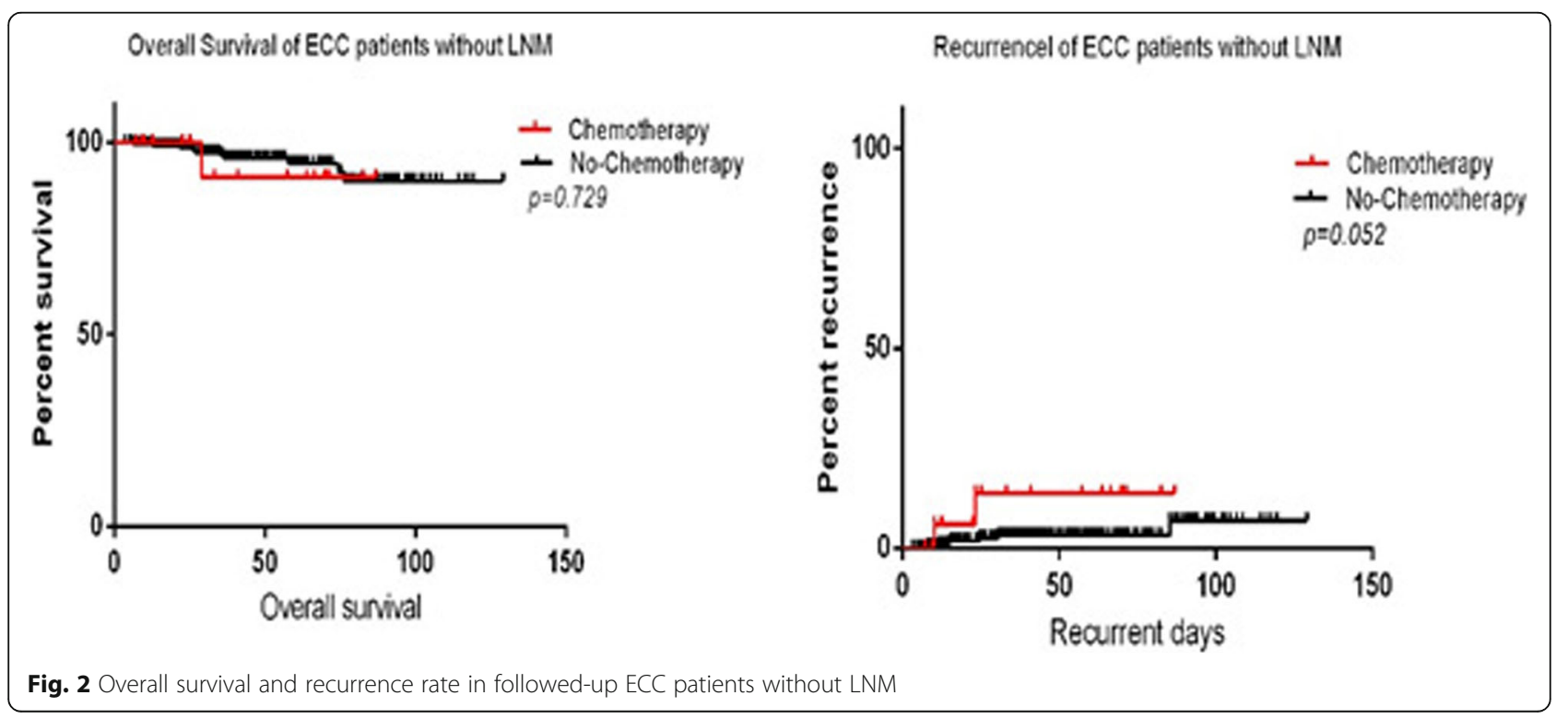


Table 3 Base-line of the ECC patients with and without LNM after matching

\begin{tabular}{|c|c|c|c|c|}
\hline Factors & $\mathrm{N} n=34$ & $\operatorname{LNM}(-) n=17$ & $\operatorname{LNM}(+) N=17$ & $P$-value \\
\hline Gender & & & & 0.730 \\
\hline Male & 15 & 7 & 8 & \\
\hline Female & 19 & 10 & 9 & \\
\hline Age (years old) & $57.1 \pm 11.4$ & $57.5 \pm 12.3$ & $56.8 \pm 11.2$ & 0.851 \\
\hline Chemotherapy & & & & $0.034^{*}$ \\
\hline Negative & 27 & 16 & 11 & \\
\hline Positive & 7 & 1 & 6 & \\
\hline Smoking & & & & 0.287 \\
\hline Negative & 30 & 14 & 16 & \\
\hline Positive & 4 & 3 & 1 & \\
\hline Alcohol & & & & 0.628 \\
\hline Negative & 29 & 14 & 15 & \\
\hline Positive & 5 & 3 & 2 & \\
\hline Family history & & & & 0.628 \\
\hline Negative & 31 & 15 & 16 & \\
\hline Positive & 3 & 2 & 1 & \\
\hline Tumor size & $38.3 \pm 17.3$ & $38.3 \pm 17.3$ & $38.3 \pm 17.3$ & 1.000 \\
\hline Tumor location & & & & 1.000 \\
\hline Rectum & 30 & 15 & 15 & \\
\hline Colon & 4 & 2 & 2 & \\
\hline Endoscopic morphology & & & & 0.480 \\
\hline I (the uplift type) & 30 & 14 & 16 & \\
\hline II (the flat type) & 1 & 1 & 0 & \\
\hline III (the concave type) & 3 & 2 & 1 & \\
\hline Pathology & & & & 0.504 \\
\hline Highly differentiated & 3 & 2 & 1 & \\
\hline Medium differentiated & 27 & 14 & 13 & \\
\hline Poorly differentiated & 4 & 1 & 3 & \\
\hline Depth of invasion & & & & 1.000 \\
\hline Mucosal layer & 4 & 2 & 2 & \\
\hline Submucosal layer & 30 & 15 & 15 & \\
\hline Negative & 30 & 17 & 13 & \\
\hline Positive & 4 & 0 & 4 & \\
\hline
\end{tabular}

Note: * $P<0.05$, LNM(-):No lymph node metastasis, LNM(+):Lymph node metastasis

chemotherapy $(P=0.034<0.05)$ and exhibited lymphovascular invasion $(P=0.033<0.05)$ than ECC patients with negative LNM. The Kaplan-Meier analysis showed that there were no significant differences in overall survival and recurrence rates between the ECC patients with LNM and without LNM (Fig. 3).

\section{Discussion}

Early colorectal cancer is defined as an invasive adenocarcinoma of any size invading into, but not beyond, the submucosa with or without LNM. According to the
2000 cancer classification criteria of the WHO, when a tumor invades only the submucosa (pT1), it is defined as ECC. However, carcinoma in situ (Tis) and intramucosal carcinoma are customarily classified as ECC in China and Japan because their characteristics differ from those in Western countries. In total, 19 carcinomas in the epithelial layer, 57 carcinomas in the mucosal layer and 212 submucosal carcinoma cases were included in our study. In our study, the rate of LNM occurrence among the ECC cases was 5.90\% (17/288). The rate of LNM has been previously reported to range from 7 to $15 \%$ [5-8], 
Overall Survival of ECC patents after match

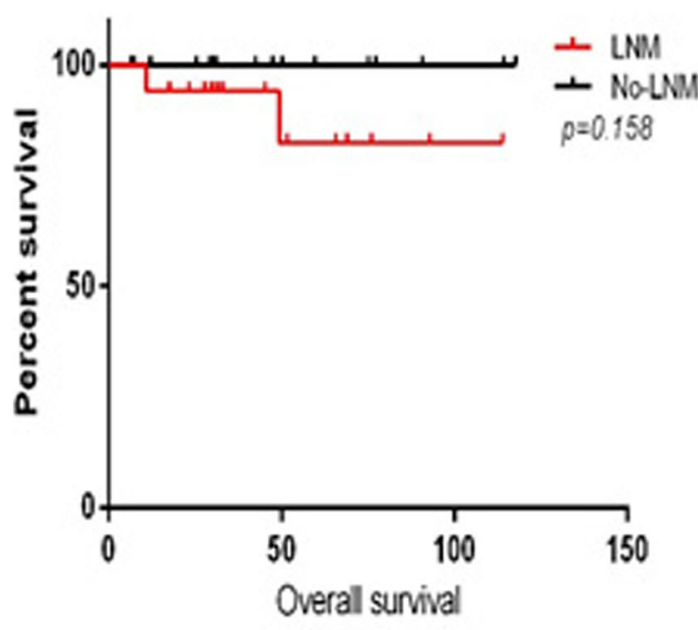

Recurrence of ECC patients after match

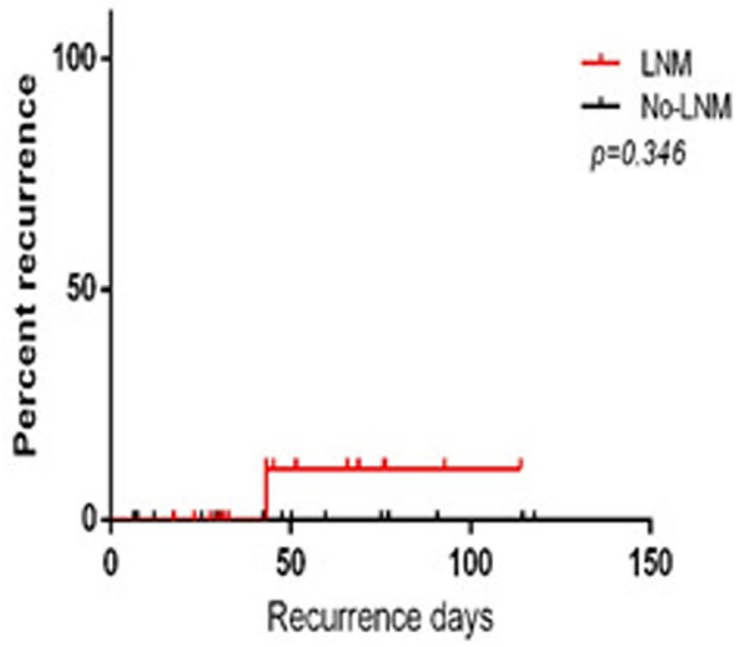

Fig. 3 Overall survival and recurrence rate in followed-up ECC patients with and without LNM after matching

which is higher than our findings. Previously, it has been established that LNM may be highly correlated with lymphovascular invasion [10, 11], tumor size [12-17], TB [18], tumor invasion in the submucosa [19-23] and pathological differentiation [24-26]. In our study, lymphovascular invasion was identified as an independent risk factor for LNM in ECC. Moreover, the incidence of lymphovascular invasion in ECC patients with LNM was $23.53 \%$, while that in the no-LNM patients was $0.74 \%$ $(P<0.001)$. In addition, the poorly differentiated cases accounted for $2.78 \%(8 / 288)$ of all cases. Our study confirmed that lymphovascular invasion, tumor size and pathological differentiation are risk factors for LNM in ECC patients by a multivariate logistic regression analysis. However, the pathological differentiation of the tumor is the most reliable predictor of LNM, which is supported by a meta-analysis of ECC [26]. As other studies have shown [27, 28], we found that the depth of tumor invasion in ECC patients was not related to LNM $(P=0.255>0.05)$. Some molecular alterations, such as P53, mitochondrial transcription factor A (TFAM), transforming growth factor (TGF)- $\beta$, adenomatosis polyposis coli (APC), mucin 2 (MUC2), hsa-miR-9-1, etc., might contribute to LNM in ECC patients [29-32]. Currently, whether chemotherapy is needed for ECC patients after tumor resection is still unclear. The National Comprehensive Cancer Network (NCCN) and Japanese Society for Cancer of the Colon and Rectum (JSCCR) guidelines recommend that local removal and regular follow-up are the standard treatments for selected ECC patients at the TisNOM0 and T1N0M0 stages [4, 31-34], while ECC patients with LNM are suggested to receive adjuvant chemotherapy after curative surgery. Among the ECC patients without LNM, chemotherapy did not seem to be beneficial for improving the overall survival and recurrence rates (Fig. 2).

However, Seyed Reza, et al. [35] found that the current guidelines for chemotherapy in T1N1M0 might not be necessary. Furthermore, we matched the LNM-ECC patients to other no-LNM patients according to the baseline measures (Table 3). More patients in the LNM group $(64.71 \%)$ chose adjuvant chemotherapy than in the no-LNM group $(5.88 \%, P=0.034<0.05)$. In these two groups, chemotherapy was the only difference. Moreover, we found that there were no significant differences in overall survival and recurrence rates between the matched LNM and no-LNM groups (Fig. 3). Thus, our study finds that adjuvant chemotherapy could improve overall survival and reduce the recurrence rate in ECC patients with LNM. For advanced colorectal cancer, the treatments include systemic and targeted therapy (including immunotherapy). Targeted therapies consist of anti-tumor angiogenesis, anti-EGFR therapy, tumor immunoregulatory inhibitors, anti-BRAF therapy, and anti-HER-2 therapy [36].

In conclusion, this study shows that tumor size, pathological differentiation and lymphovascular invasion are the main risk factors for LNM in patients with ECC. The decision regarding whether to choose surgical or endoscopic resection should be made after considering the potential risks of LNM. However, the suggestion that ECC patients with LNM should receive adjuvant chemotherapy is still controversial. Our results verify that postoperative chemotherapy is necessary for ECC patients with LNM but might not be helpful for ECC patients without LNM. However, there are also some limitations in present study. 
First, a relatively small sample size was included in this retrospective study, and only 20 ECC patients without LNM received postoperative chemotherapy. Thus, it might be difficult to precisely estimate the association between postoperative chemotherapy and prognosis in LNM-negative ECC. Second, although both main chemotherapy regimens consist of a same key chemotherapeutic drug (Oxaliplatin), there may be still certain discrepancies in the curative effects between various regimens.

\section{Conclusion}

In summary, tumor size, pathology, and lymphovascular invasion are risk factors for predicting LNM in ECC patients. We believe that it could be better and necessary for patients with ECC to undergo a full LNM evaluation before choosing surgical or endoscopic resection according to the risk factors of LNM, such as tumor size, pathology, and lymphovascular invasion. We confirmed that chemotherapy could improve overall survival and recurrence in ECC patients with LNM after resection, while it may be unnecessary for ECC patients without LNM to receive chemotherapy after tumor resection. Considering these above limitations, this result should be interpreted with caution, and further well-designed, prospective, large sample study is imperative to verify the association between postoperative chemotherapy and prognosis in ECC patients without LNM.

\section{Abbreviations}

LNM: Lymph node metastasis; ECC: Early colorectal cancer; TB: Tumor budding; NCCN: National Comprehensive Cancer Network; L-

OHP: Oxaliplatin; CAP: Capecitabine; CF: Calcium folinate; 5-FU: 5-fluorouracil; Chemo: Chemotherapy; TFAM: Mitochondrial transcription factor A; TGF$\beta$ : Transforming growth factor- $\beta$; APC: Adenomatosis polyposis coli
}

\section{Acknowledgments}

The grant No. 81660404 to CZ and No. 81560398 to YC, grant No. GJJ170016 to CZ and grant No. $20201 Z D G 02007$ to YC.

\section{Declarations}

None.

\section{Authors' contributions}

CZ, DX and FC contributed equally to this work; All of the authors have made substantial contributions to the conception; $C Z, F C, D X$ and $Y C$ designed the study and drafted the manuscript; FC, DX, QL, QW and JH made a great contribution to the acquisition and analysis of the data; $\mathrm{CZ}, \mathrm{GL}$ and $\mathrm{HZ}$ also analyzed the data and made a great work on the interpretation of the data; $\mathrm{CZ}$ and $\mathrm{YC}$ revised the manuscript for important intellectual content; $C Z$ and $Y C$ made substantial contributions to design and coordination of the study and gave final approval of the version to be published. All authors have read and approved the final manuscript.

\section{Funding}

This study was supported by grants from the National Natural Science Foundation of China (Grant No. 81660404 and No. 81560398), the Foundation of Jiangxi Educational Committee (grant No. GJJ170016) and the Foundation of Jiangxi provincial department of Science and Technology (grant No. 20201ZDG02007). These funding bodies had no role in the design of the study and collection, analysis, interpretation of data and in writing the manuscript.

\section{Availability of data and materials}

All analyzed data are included in this published article. The original data are available upon reasonable request to the corresponding author.

\section{Ethics approval and consent to participate}

The clinical data was acquired with the approval and permission of the Institutional Review Board of the First Affiliated Hospital of Nanchang University. The study protocol was approved by the Institutional Review Board of the First Affiliated Hospital of Nanchang University. Informed consent was not required because this study was a retrospective report of cases, which is a retrospective analysis of clinical data with no relevant to human biological ethic problems.

Consent for publication

Not applicable.

\section{Competing interests}

The authors have no conflicts of interest to declare.

\section{Author details}

'Department of Gastroenterology, the First Affiliated Hospital of Nanchang University, 17 Yongwaizheng Street, Nanchang 330006, Jiangxi, China.

${ }^{2}$ Department of Gastroenterology, the Third Affiliated Hospital of Nanchang University, Nanchang, China. ${ }^{3}$ Department of Gastroenterology, the Affiliated Ganzhou Hospital of Nanchang University, Ganzhou, China. ${ }^{4}$ Department of Gastroenterology, Jiangxi Provincial People's Hospital, Nanchang, China.

${ }^{5}$ Department of Gastroenterology, Jiangxi Cancer Hospital, Nanchang, China.

${ }^{6}$ Department of Biology, Hong Kong Baptist University, Hong Kong, China.

Received: 24 April 2020 Accepted: 31 August 2020

Published online: 05 November 2020

\section{References}

1. Gupta AK, Melton LR, Petersen GM, et al. Changing trends in the incidence, stage, survival, and screen-detection of colorectal cancer: a populationbased study []]. Clin Gastroenterol Hepatol. 2005;3(2):150-8.

2. Kyzer S, Begin LR, Gordon PH, et al. The care of patients with colorectal polyps that contain invasive adenocarcinoma. Endoscopic polypectomy or colectomy? Cancer. 1992;70(8):2044-50.

3. Morson BC, Whiteway JE, Jones EA, et al. Histopathology and prognosis of malignant colorectal polyps treated by endoscopic polypectomy [J]. Gut. 1984;25(5):437-44

4. Watanabe T, Muro K, Ajioka Y, et al. Japanese Society for Cancer of the Colon and Rectum (JSCCR) guidelines 2016 for the treatment of colorectal cancer [J]. Int J Clin Oncol. 2018;23(1):1-34.

5. Kikuchi $\mathrm{R}$, Takano M, Takagi $\mathrm{K}$, et al. Management of early invasive colorectal cancer. Risk of recurrence and clinical guidelines [J]. Dis Colon Rectum. 1995;38(12):1286-95

6. Tominaga K, Nakanishi Y, Nimura S, et al. Predictive histopathologic factors for lymph node metastasis in patients with nonpedunculated submucosal invasive colorectal carcinoma []]. Dis Colon Rectum. 2005;48(1):92-100.

7. Sohn DK, Chang HJ, Park JW, et al. Histopathological risk factors for lymph node metastasis in submucosal invasive colorectal carcinoma of pedunculated or semipedunculated type [J]. J Clin Pathol. 2007;60(8):912-5.

8. Okabe S, Shia J, Nash G, et al. Lymph node metastasis in T1 adenocarcinoma of the colon and rectum [J]. J Gastrointest Surg. 2004;8(8): $1032-40$.

9. Dienstmann R, Salazar R, Tabernero J. Personalizing colon cancer adjuvant therapy: selecting optimal treatments for individual patients. J Clin Oncol. 2015;33(16):1787-96

10. Machado I, Valera-Alberni M. Martínez de Juan F, et al: histological factors predicting loco-regional lymph node metastasis in early invasive colorectal adenocarcinoma pT1. Gastroenterol Hepatol. 2016;39(1):1-8.

11. Krasna MJ, Flancbaum L, Cody RP, et al. Vascular and neural invasion in colorectal carcinoma. Incidence and prognostic significance [J]. Cancer. 1988;61(5):1018-23.

12. Gangireddy VGR, Coleman T, Kanneganti P, et al. Polypectomy versus surgery in early colon cancer: size and location of colon cancer affect longterm survival. Int J Color Dis. 2018;33(10):1349-57. 
13. Zhang H, Chen CS, Cong JC, et al. Clinicopathological characteristics of advanced colorectal cancer $30 \mathrm{~mm}$ or smaller in diameter. Chin Med Sci J. 2007;22(2):98-103

14. Wang HS, Liang WY, Lin TC, et al. Curative resection of T1 colorectal carcinoma: risk of lymph node metastasis and long-term prognosis []]. Dis Colon Rectum. 2005;48(6):1182-92.

15. Yasuda K, Inomata M, Shiromizu A, et al. Risk factors for occult lymph node metastasis of colorectal cancer invading the submucosa and indications for endoscopic mucosal resection [J]. Dis Colon Rectum. 2007;50(9):1370-6.

16. Aldecoa I, Atares B, Tarragona J, et al. Molecularly determined total tumour load in lymph nodes of stage I-II colon cancer patients correlates with high-risk factors. A multicentre prospective study. Virchows Arch. 2016;469(4):385-94.

17. Yamauchi H, Togashi K. Kawamura Y J, et al: pathological predictors for lymph node metastasis in T1 colorectal cancer []]. Surg Today. 2008;38(10):905-10.

18. Brown lan S, Bettington Mark L. Bettington Andrew, et al: adverse histological features in malignant colorectal polyps: a contemporary series of 239 cases. J Clin Pathol. 2016;69(4):292-9.

19. Sakuragi M, Togashi K, Konishi F, et al. Predictive factors for lymph node metastasis in T1 stage colorectal carcinomas [J]. Dis Colon Rectum. 2003; 46(12):1626-32.

20. Son HJ, Song SY, Lee WY, et al. Characteristics of early colorectal carcinoma with lymph node metastatic disease []]. Hepatogastroenterology. 2008; 55(85):1293-7.

21. Tateishi Y, Nakanishi Y, Taniguchi H, et al. Pathological prognostic factors predicting lymph node metastasis in submucosal invasive (T1) colorectal carcinoma [J]. Mod Pathol. 2010;23(8):1068-72.

22. Choi PW, Yu CS, Jang SJ, et al. Risk factors for lymph node metastasis in submucosal invasive colorectal cancer [J]. World J Surg. 2008;32(9):2089-94.

23. Egashira Y, Yoshida T, Hirata I, et al. Analysis of pathological risk factors for lymph node metastasis of submucosal invasive colon cancer [J]. Mod Pathol. 2004;17(5):503-11.

24. Williams JG, Pullan RD, Hill J, et al. Management of the malignant colorectal polyp: ACPGBI position statement [J]. Color Dis. 2013;(Suppl 2):1-38.

25. Hassan C, Zullo A, Risio M, et al. Histologic risk factors and clinical outcome in colorectal malignant polyp: a pooled-data analysis [J]. Dis Colon Rectum. 2005;48(8):1588-96.

26. Beaton $C$. Twine $C P$, Williams $G L$, et al: systematic review and metaanalysis of histopathological factors influencing the risk of lymph node metastasis in early colorectal cancer [J]. Color Dis. 2013;15(7):788-97.

27. Oka S, Tanaka S, Nakadoi K, et al. Risk analysis of submucosal invasive rectal carcinomas for lymph node metastasis to expand indication criteria for endoscopic resection [J]. Dig Endosc. 2013;25(Suppl 2):21-5.

28. Suh $\mathrm{JH}$, Han $\mathrm{KS}$, Kim BC, et al. Predictors for lymph node metastasis in $\mathrm{T1}$ colorectal cancer [J]. Endoscopy. 2012:44(6):590-5.

29. Wen $S$, Gao J, Zhang L, et al. p53 increase mitochondrial copy number via up-regulation of mitochondrial transcription factor A in colorectal cancer. Oncotarget. 2016;7(46):75981-95.

30. Kim JC, Cho YK, Seon A. Roh, et al. Blackwell publishing Asia individual tumorigenesis pathways of sporadic colorectal adenocarcinomas are associated with the biological behavior of tumors. Cancer Sci. 2008;99(7):1348-54.

31. Hanski C, Riede E, Gratchev A, et al. MUC2 gene suppression in human colorectal carcinomas and their metastases: in vitro evidence of the modulatory role of DNA methylation. Lab Investig. 1997;77(6):685-95.

32. Bandres E, Agirre X, Bitarte N, Ramirez N, Zarate R, Roman-Gomez J, Prosper $\mathrm{F}$, Garcia-Foncillas J. Epigenetic regulation of microRNA expression in colorectal Cancer. Int J Cancer. 2009;125(11):2737-43.

33. Provenzale D, Gupta S. Ahnen D J, et al: NCCN guidelines insights: colorectal Cancer screening, version 1. J Natl Compr Cancer Netw. 2018;16(8):939-49.

34. Benson AB, Venook AP, Al-Hawary MM, et al. NCCN guidelines insights: Colon Cancer, version 2.2018. J Natl Compr Cancer Netw. 2018;16(4):359-69.

35. Fatemi SR, Pourhoseingholi MA, Asadi F, et al. Recurrence and Five -Year Survival in Colorectal Cancer Patients After Surgery. Iran J Cancer Prev. 2015;8(4):e3439.

36. Hegde SR, Sun W, Lynch JP. Systemic and targeted therapy for advanced colon cancer. Expert Rev Gastroenterol Hepatol. 2008;2(1):135-49.

\section{Publisher's Note}

Springer Nature remains neutral with regard to jurisdictional claims in published maps and institutional affiliations.

\section{Ready to submit your research? Choose BMC and benefit from:}

- fast, convenient online submission

- thorough peer review by experienced researchers in your field

- rapid publication on acceptance

- support for research data, including large and complex data types

- gold Open Access which fosters wider collaboration and increased citations

- maximum visibility for your research: over $100 \mathrm{M}$ website views per year

At BMC, research is always in progress.

Learn more biomedcentral.com/submissions 